\title{
Cationic Copolymerization of Divinyl Ethers with Vinyl Ether. Synthesis and Cation-Binding Property of Copolymer with Benzo-19-Crown-6 Units
}

\author{
Toyoji KaKUCHI, ${ }^{*}$ Katsutoshi AoKI, Osamu HaBA, \\ and Kazuaki YокотA* \\ Department of Chemical Process Engineering, Faculty of Engineering, \\ Hokkaido University, Sapporo 060, Japan
}

(Received February 4, 1993)

\begin{abstract}
Copolymerizations of 1,2-bis(2-vinyloxyethoxy)benzene (BVEB) and 1,2-bis[2(2-vinyloxyethoxy)ethoxy] benzene (BVEEB) with isobutyl vinyl ether (IBVE) were carried out with $\mathrm{BF}_{3} \cdot \mathrm{OEt}_{2}, \mathrm{SnCl}_{4}$, and $\mathrm{I}_{2}$ in dichloromethane, nitroethane, and toluene. The copolymers obtained were gel-free and did not contain any residual vinyloxy groups though the excess amount of IBVE in monomer feed such as the [IBVE]/[BVEB] ratio of 9 . The copolymerization parameters were $r_{1}=1.09$ and $r_{2}=0.86$ for BVEB $\left(\mathrm{M}_{1}\right)$-IBVE $\left(\mathrm{M}_{2}\right)$, and $r_{1}=1.23$ and $r_{2}=0.92$ for BVEEB $\left(\mathrm{M}_{1}\right)$-IBVE $\left(\mathrm{M}_{2}\right)$. The copolymers consisting of BVEEB and IBVE, i.e., poly[(benzo-19-crown6)-co-IBVE]s, showed the cation-binding property as $\mathrm{K}^{+}, \mathrm{Rb}^{+}$, and $\mathrm{Cs}^{+} \gg \mathrm{Li}^{+}$and $\mathrm{Na}^{+}$, regardless of the mole fraction of the crown ether unit.

KEY WORDS Cyclopolymerization / Copolymerization / Cationic Initiator / $\alpha, \omega$-Divinylether / Isobutyl Vinyl Ether / Copolymerization Parameter / Benzo-19-Crown-6 / Cation-Binding Property / Alkali Metal Picrate/
\end{abstract}

Butler and Lien, ${ }^{1}$ Mathias and Canterberry, ${ }^{2}$ and $\mathrm{we}^{3}$ presented one of the simplest avenues to the synthesis of poly(crown ether)s by cationic cyclopolymerization of $\alpha, \omega$-divinylethers. The characteristics of the cyclopolymerization method are followings: (a) cyclic derivative does not need as a monomer; (b) macrocyclic units and polymer chains are formed at the same time; (c) monomers incorporating various designed units are easily synthesized and polymerized with a conventional initiator. ${ }^{4,5}$ Rodenhouse et al. ${ }^{6}$ and we ${ }^{7}$ reported the cationic copolymerization of 1,2bis(2-vinyloxyethoxy)benzene (BVEB) with vinyl ether proceeded without gelation to produce copolymers with crown ether units.

On the other hand, Butler reported that divinyl ether with maleic anhydride (MAn) and of BVEB with MAn copolymerized with radical initiator to form 1:2 alternating cyclocopoly- mers. $^{1,8}$ This kind of copolymerization is classified as cyclocopolymerization. The intermediate charge-transfer complex between divinyl ethers and MAn plays a significant role in controlling the alternating copolymerization. Then the present study aims at elucidating the property of the cationic copolymerization of $\alpha, \omega$-divinylether with vinyl ether.

In host-guest complexation, poly(benzo19-crown-6), prepared by the cationic cyclopolymerization of 1,2-bis[2-(2-vinyloxyethoxy)ethoxy]benzene (BVEEB), exhibited the highest selectivity for $\mathrm{Rb}^{+}$by forming a 2:1 crown-cation complex. Of interest, therefore, is the cation-binding property of a copolymer with crown ether units.

In this paper, we report the copolymerization tendency of BVEB with isobutyl vinyl ether (IBVE) by use of conventional cationic initiators, the synthesis of copolymers with 

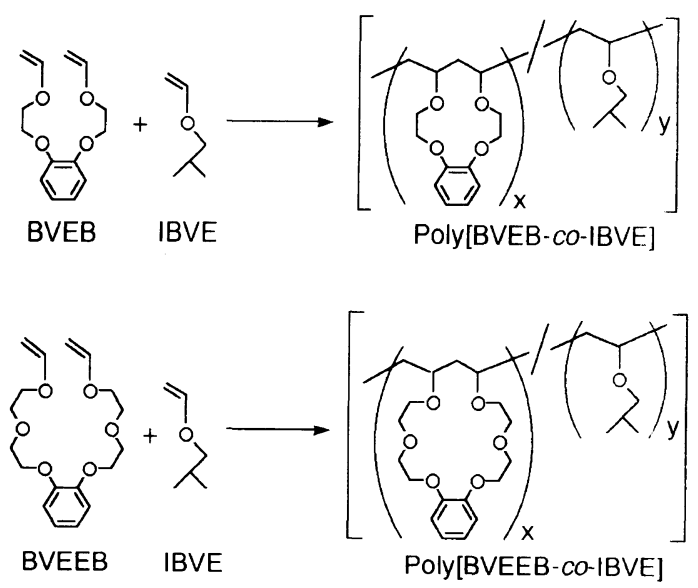

Scheme 1.

different mole fraction of benzo-19-crown-6 units by the copolymerization of BVEEB with IBVE, (Scheme 1) and the copolymerization parameters for $\alpha, \omega$-divinylethers and IBVE. In addition, the binding property of poly(BVEEBco-IBVE)s toward alkali-metal picrates was examined.

\section{EXPERIMENTAL}

\section{Materials}

The syntheses of 1,2-bis(2-vinyloxyethoxy)benzene (BVEB) and 1,2-bis[2-(2-vinyloxyethoxy)ethoxy] benzene (BVEEB) were reported in previous papers. ${ }^{1,3}$ Isobutyl vinyl ether (IBVE) was obtained from Aldrich and distiled over calcium hydride under reduced pressure. Boron trifluoride etherate $\left(\mathrm{BF}_{3} \cdot \mathrm{OEt}_{2}\right)$ and tin(IV) chloride $\left(\mathrm{SnCl}_{4}\right)$ were purified by distillation of commercial products under reduced pressure. Iodine $\left(\mathrm{I}_{2}\right)$ was sublimed over potassium iodide under reduced pressure. $\mathrm{BF}_{3} \cdot \mathrm{OEt}_{2}, \mathrm{SnCl}_{4}$, and $\mathrm{I}_{2}$ were used as a solution in dichloromethane. Dichloromethane, nitroethane, and toluene were purified by the usual methods and distiled over calcium hydride.

\section{Measurements}

${ }^{1} \mathrm{H}$ and ${ }^{13} \mathrm{C}$ NMR spectra were recorded with a Hitachi R $90 \mathrm{H}$ and a Brucker MSL 400 instruments. UV spectra were recorded on a Jasco 660 UV/VIS spectrophotometer. The molecular weight of the resulting copolymers were measured by gel permeation chromatograph (GPC) in tetrahydrofurane on a Waters M45 high-performance liquid chromatography equipped with three polystyrene gel columns (Shodex KF-804L). The number-average molecular weight $\left(\bar{M}_{n}\right)$ was calculated on the basis of a polystyrene calibration.

\section{Typical Copolymerization Procedure}

To a solution of $357 \mathrm{mg}(1.43 \mathrm{mmol})$ of BVEB and $145 \mathrm{mg}(1.44 \mathrm{mmol})$ of IBVE in $14.3 \mathrm{ml}$ of dichloromethane was added $7 \mu \mathrm{l}$ of $\mathrm{BF}_{3} \cdot \mathrm{OEt}_{2}$ in dichloromethane $\left(0.962 \mathrm{moll}^{-1}\right)$ at $0^{\circ} \mathrm{C}$. After $24 \mathrm{~h}$, the reaction mixture poured into $100 \mathrm{ml}$ of methanol. The methanolinsoluble product was separated, resolved into chloroform, and poured into methanol. After separating from methanol and drying in vacuum for $24 \mathrm{~h}, 411 \mathrm{mg}$ of the brittle copolymer was obtained (yield, $82 \%$ ). The molecular weight and the mole fraction of BVEB units are listed in Table I, and the ${ }^{1} \mathrm{H}$ and the ${ }^{13} \mathrm{C}$ NMR spectra are shown in Figure 1.

\section{Copolymer Composition}

The composition in copolymers was determined by the relative area ratio between the methyl protons for IBVE units and the phenyl ones for BVEB or BVEEB units in the ${ }^{1} \mathrm{H}$ NMR spectra.

\section{Cation-Binding Property}

A solution of polymer in dichloromethane ([crown ether units] $=3.5 \times 10^{-3} \mathrm{moll}^{-1}$ ) was vigorously shaken in a culture tube with the aqueous solution of alkali-metal hydroxide and picric acid ([picric acid] $=7 \times 10^{-5} \mathrm{moll}^{-1}$, [alkali-metal hydroxide] $=0.1 \mathrm{moll}^{-1}$ ). After the resulting two phases were separated, the alkali-metal picrate extracted into the dichloromethane was indirectly determined by measuring the absorbance of picrate in the 
Table I. Copolymerization of 1,2-bis(2-vinyloxyethoxy)benzene (BVEB) and isobutyl vinyl ether (IBVE) ${ }^{\mathrm{a}}$

\begin{tabular}{llccrc}
\hline \multirow{2}{*}{ Catalyst } & Solvent & \begin{tabular}{c} 
Yield \\
\cline { 2 - 5 }
\end{tabular} & $\begin{array}{c}\text { Mole fraction } \\
\text { of BVEB units } \\
\text { in copolymer }\end{array}$ & $\begin{array}{c}\bar{M}_{n}^{\mathrm{c}} \\
\times 10^{-3}\end{array}$ & $\bar{M}_{w} / \bar{M}_{n}{ }^{\mathrm{c}}$ \\
\hline $\mathrm{BF}_{3} \cdot \mathrm{OEt}_{2}$ & $\mathrm{CH}_{2} \mathrm{Cl}_{2}$ & 82 & 0.59 & 6.0 & 2.10 \\
& $\mathrm{C}_{6} \mathrm{H}_{5} \mathrm{CH}_{3}$ & 89 & 0.56 & 12.0 & 2.75 \\
$\mathrm{C}_{2} \mathrm{H}_{5} \mathrm{NO}_{2}$ & 76 & 0.57 & 4.6 & 1.70 \\
$\mathrm{SnCl}_{4}$ & $\mathrm{CH}_{2} \mathrm{Cl}_{2}$ & 64 & 0.62 & 11.6 & 1.46 \\
& $\mathrm{C}_{6} \mathrm{H}_{5} \mathrm{CH}_{3}$ & 59 & 0.58 & 20.5 & 2.19 \\
$\mathrm{I}_{2}$ & $\mathrm{C}_{2} \mathrm{H}_{5} \mathrm{NO}_{2}$ & 55 & 0.58 & 4.5 & 1.49 \\
& $\mathrm{CH}_{2} \mathrm{Cl}_{2}$ & 64 & 0.63 & 11.3 & 1.51 \\
& $\mathrm{C}_{6} \mathrm{H}_{5} \mathrm{CH}_{3}$ & 17 & 0.82 & 4.4 & 1.41 \\
& $\mathrm{C}_{2} \mathrm{H}_{5} \mathrm{NO}_{2}$ & 57 & 0.86 & 3.6 & 1.70 \\
\hline
\end{tabular}

${ }^{\mathrm{a}}[\mathrm{BVEB}]=[\mathrm{IBVE}]=0.1 \mathrm{~mol}^{-1}$; [Cat. $]=0.5 \mathrm{mmol}^{-1}$; temp, $0^{\circ} \mathrm{C}$; time $24 \mathrm{~h}$.

${ }^{b}$ Determined by ${ }^{1} \mathrm{H}$ NMR spectra.

c Determined by GPC (polystyrene standard).

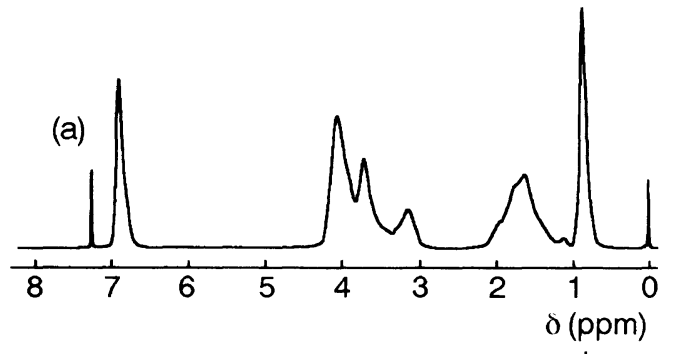

(b)

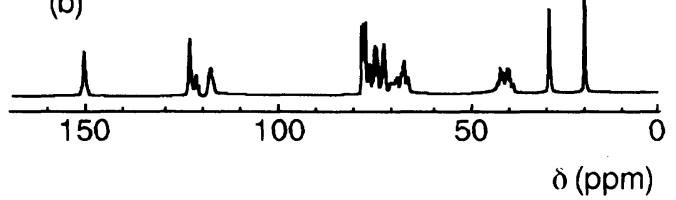

Figure 1. ${ }^{1} \mathrm{H}$ (a) and ${ }^{13} \mathrm{C}$ (b) NMR spectra of the copolymer prepared by the copolymerization of 1,2-bis(2vinyloxyethoxy)benzene (BVEB) with isobutyl vinyl ether (IBVE) with $\mathrm{BF}_{3} \cdot \mathrm{OEt}_{2}$ in $\mathrm{CH}_{2} \mathrm{Cl}_{2}$ at $0^{\circ} \mathrm{C}$ : [BVEB] $=$ $\left[\right.$ IBVE] $=0.1 \mathrm{~mol} \mathrm{l}^{-1}$; [Cat.] $=0.5 \mathrm{mmol} \mathrm{l}^{-1}$; time, $24 \mathrm{~h}$.

aqueous phase at $357 \mathrm{~nm}$ using a UVspectrophotometer.

\section{RESULTS AND DISCUSSION}

\section{Cationic Copolymerization of BVEB and IBVE}

In the homopolymerization of $\alpha, \omega$-divinyl- ethers, $\mathrm{BF}_{3} \cdot \mathrm{OEt}_{2}, \mathrm{SnCl}_{4}, \mathrm{TiCl}_{4}, \mathrm{I}_{2}, \mathrm{HI} / \mathrm{I}_{2}$, $\mathrm{AlEtCl}_{2}$, and $\mathrm{AlEt}_{2} \mathrm{Cl}$ are effective as conventional and effective cationic initiators. $\mathrm{BF}_{3}$. $\mathrm{OEt}_{2}$ and $\mathrm{SnCl}_{4}$ in dichloromethane and nitroethane at $0^{\circ} \mathrm{C}$ are particularly suitable for producing gel-free poly(crown ether)s in high yield. The conditions best fitted for the homopolymerization, therefore, were applied to the copolymerization of 1,2-bis(2-vinyloxyethoxy)benzene (BVEB) with isobutyl vinyl ether (IBVE). ${ }^{5}$

Table I lists the results of the copolymerization of BVEB and IBVE ([BVEB] $=[$ IBVE $]$ ) with $\mathrm{BF}_{3} \cdot \mathrm{OEt}_{2}, \mathrm{SnCl}_{4}$, and $\mathrm{I}_{2}$ in $\mathrm{di}-$ chloromethane, toluene, and nitroethane. All the copolymerizations proceeded homogeneously. The copolymers obtained were brittle and soluble in benzene, chloroform, and THF. Because the GPC traces of resulting copolymers with UV and RI detections corresponded to each other, the copolymers contain no homopolymer. The copolymer yields with $\mathrm{BF}_{3} \cdot \mathrm{OEt}_{2}$ were higher than those with $\mathrm{SnCl}_{4}$ and $\mathrm{I}_{2}$. A maximum yield of $89 \%$ was obtained for $\mathrm{BF}_{3} \cdot \mathrm{OEt}_{2} /$ toluene, and a minimum one of $17 \%$ for $\mathrm{I}_{2} /$ toluene. The number average molecular weight $\left(\bar{M}_{n}\right)$ of the obtained polymers was from 3600 to 20500 . The 
Table II. Effect of monomer concentration on the copolymerization of 1,2-bis(2-vinyloxyethoxy)benzene (BVEB) and isobutyl vinyl ether (IBVE) with $\mathrm{BF}_{3} \cdot \mathrm{OEt}_{2}$ in $\mathrm{CH}_{2} \mathrm{Cl}_{2}$ at $0^{\circ} \mathrm{C}^{\mathrm{a}}$

\begin{tabular}{|c|c|c|c|c|c|}
\hline [BVEB] & [Cat.] & Time & Yield & Mole fraction & $\bar{M}_{n}^{c}$ \\
\hline $\operatorname{mol} 1^{-1}$ & $\mathrm{mmol}^{-1}$ & $\min$ & $\%$ & in copolymer ${ }^{\mathbf{b}}$ & \\
\hline 0.05 & 0.5 & 40 & 19 & 0.61 & 8.7 \\
\hline 0.10 & 1.0 & 10 & 14 & 0.60 & 5.8 \\
\hline 0.15 & 1.5 & 8 & 24 & 0.58 & 12.7 \\
\hline 0.20 & 1.5 & 10 & 27 & 0.56 & 8.8 \\
\hline 0.25 & 1.5 & 1 & 18 & 0.60 & 9.0 \\
\hline 0.30 & 1.5 & 1 & Gelation & - & - \\
\hline
\end{tabular}

${ }^{\mathrm{a}}[\mathrm{BVEB}]=[\mathrm{IBVE}]$.

b Determined by ${ }^{1} \mathrm{H}$ NMR spectra.

c Determined by GPC (polystyrene standard).

polymers with $\mathrm{BF}_{3} \cdot \mathrm{OEt}_{2}$ and $\mathrm{SnCl}_{4}$ in toluene had the relatively high $\bar{M}_{n}$ s of 12000 and 20500 , respectively. The molecular weight distributions, however, were broad to be the $\bar{M}_{w} / \bar{M}_{n}$ ratios of 2.75 and 2.19 , and their GPC traces were multimodal.

Figure 1 shows the ${ }^{1} \mathrm{H}$ and the ${ }^{13} \mathrm{C}$ NMR spectra of the copolymer obtained with $\mathrm{BF}_{3} \cdot \mathrm{OEt}_{2}$ in dichloromethane. The characteristic absorptions at $6.3-6.6 \mathrm{ppm}$ due to the vinyloxy protons and at 86.7 and $151.6 \mathrm{ppm}$ due to the vinyl carbons had completely disappeared, and thus BVEB polymerized with $100 \%$ cyclization. The copolymers obtained under other conditions also contained no residual vinyloxy bonds. The incorporation of the comonomer, IBVE, never inhibited the intramolecular cyclization of BVEB. Since the cyclopolymerization of divinyl ether with a cationic initiator proceeds through a head-totail addition, ${ }^{6}$ the cyclic constitutional units in the copolymer is benzo-13-crown-4. The composition in copolymers was determined by the relative area ratio between the methyl and the phenyl protons. The mole fraction of BVEB units in the copolymers showed a little variation in value of 0.56 to 0.63 except for the shift to the values of 0.82 and 0.86 in the copolymers obtained with $\mathrm{I}_{2}$ in toluene and nitroethane, respectively.
Monomer concentration is a generally important factor for affecting the cyclopolymerization tendency of bifunctional monomers. In the homopolymerization of divinyl ethers, the polymers with residual vinyloxy bonds are occasionally obtained and/or the polymerization is accompanied with gelation at the monomer concentration ([M]) of $0.5 \mathrm{~mol} \mathrm{l}^{-1}$ or above. On the other hand, the polymerization rate is extremely slow or the polymerization does not occur at $[\mathrm{M}]$ of $0.1 \mathrm{~mol}^{-1}$ or below. Table II lists the results of the copolymerization changing the monomer concentration at the condition of a monomer mixture of $[\mathrm{BVEB}] /[\mathrm{IBVE}]=50 / 50$ with $\mathrm{BF}_{3}$. $\mathrm{OEt}_{2}$ in dichloromethane at $0^{\circ} \mathrm{C}$. The copolymerization rate increased with increase in the monomer concentration, but the gelation finally occurred at the [BVEB] of $0.3 \mathrm{~mol}^{-1}$. The copolymers obtained at the [BVEB] of $0.25 \mathrm{~mol}^{-1}$ and below were soluble in the organic solvents, and no characteristic absorption due to the residual vinyl bonds was observed in the ${ }^{1} \mathrm{H}$ NMR spectra. There was little effect of the monomer concentration on copolymer composition.

Table III lists the results of the copolymerization using various monomer feeds at the condition of $[\mathrm{BVEB}+\mathrm{IBVE}]=0.2 \mathrm{~mol} \mathrm{l}^{-1}$ with $\mathrm{BF}_{3} \cdot \mathrm{OEt}_{2}$ in dichloromethane at $0^{\circ} \mathrm{C}$. The 
Table III. Copolymerization of 1,2-bis(2vinyloxyethoxy)benzene (BVEB) and isobutyl vinyl ether (IBVE) with $\mathrm{BF}_{3} \cdot \mathrm{OEt}_{2}$ in $\mathrm{CH}_{2} \mathrm{Cl}_{2}$ at $0^{\circ} \mathrm{C}^{a}$

\begin{tabular}{|c|c|c|c|c|}
\hline \multirow{2}{*}{$\begin{array}{l}\text { Mole fraction } \\
\text { of BVEB } \\
\text { in monomers }\end{array}$} & Time & Yield & \multirow{2}{*}{$\begin{array}{l}\text { Mole fraction } \\
\text { of BVEB units } \\
\text { in copolymer }\end{array}$} & \multirow{2}{*}{$\begin{array}{r}\bar{M}_{n}^{\mathrm{c}} \\
\times 10^{-3}\end{array}$} \\
\hline & $\mathrm{h}$ & $\%$ & & \\
\hline 0.10 & 18 & 19 & 0.10 & 5.8 \\
\hline 0.25 & 18 & 12 & 0.26 & 5.2 \\
\hline 0.40 & 0.2 & 18 & 0.48 & 4.4 \\
\hline 0.50 & 0.2 & 11 & 0.60 & 5.1 \\
\hline 0.60 & 0.1 & 25 & 0.63 & 7.5 \\
\hline 0.75 & 0.1 & 16 & 0.80 & 8.8 \\
\hline 0.90 & 1 (min) & 52 & 0.94 & 6.5 \\
\hline
\end{tabular}

${ }^{\mathrm{a}}[\mathrm{BVEB}+\mathrm{IBVE}]=0.2 \mathrm{~mol} \mathrm{1}^{-1} ;$ [Cat. $]=0.5 \mathrm{mmol}^{-1}$.

b Determined by ${ }^{1} \mathrm{H}$ NMR spectra.

c Determined by GPC (polystyrene standard).

copolymerization parameters for BVEB $\left(\mathrm{M}_{1}\right)$ and IBVE $\left(\mathrm{M}_{2}\right)$ were estimated by use of the usual Mayo-Lewis equation and the Kelen-Tüdös method, giving $r_{1}=1.09$ and $r_{2}=0.86$.

In these cases the intramolecular cyclization of BVEB perfectly proceeded as well. The uncyclized growing carbocation I eliminated the reaction with the vinyloxy group of IBVE even in the high feed ratio such as the [IBVE]/[BVEB] ratio of 9 . The high cyclopolymerization tendency of BVEB indicates that the uncyclized growing carbocation I leads predominantly the intramolecular cyclization which is extremely fast relative to the intermolecular propagations with BVEB or IBVE, thus being transformed to only the cyclized carbocation II (Scheme 2). These results strongly suggest that the intramolecular solvation of the uncyclized growing carbocation with intramolecular oxygens acts as a driving force in the cyclization mechanism (Scheme 3).

\section{Synthesis and Cation-binding Property of} Poly [(benzo-19-crown-6)-co-IBVE]s

The cyclocopolymerization tendency of 1,2bis[2-(2-vinyloxyethoxy)ethoxy]benzene

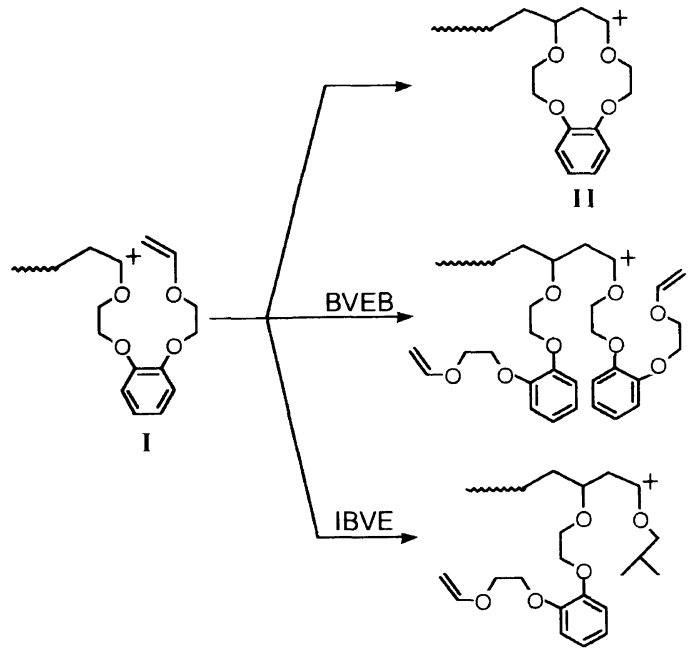

Scheme 2.

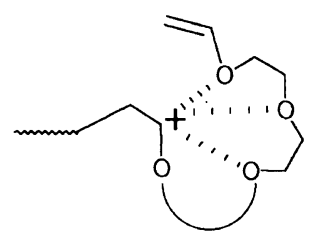

Scheme 3.

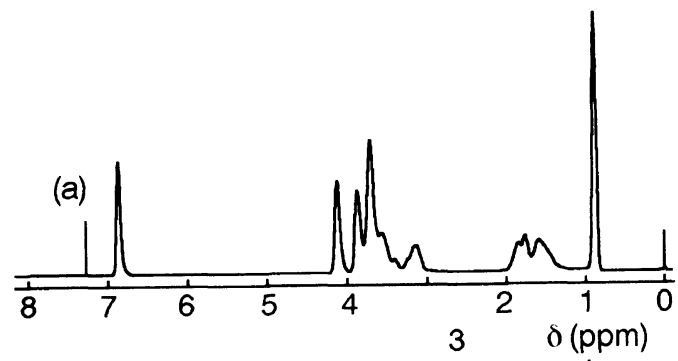

(b)

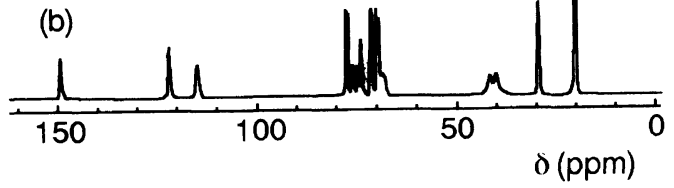

Figure 2. ${ }^{1} \mathrm{H}$ (a) and ${ }^{13} \mathrm{C}$ (b) NMR spectra of the copolymer prepared by the copolymerization of 1,2-bis[2(2-vinyloxyethoxy)ethoxy]benzene (BVEEB) with isobutyl vinyl ether (IBVE) with $\mathrm{BF}_{3} \cdot \mathrm{OEt}_{2}$ in $\mathrm{CH}_{2} \mathrm{Cl}_{2}$ at $0^{\circ} \mathrm{C}$ : the mole fraction of BVEEB in monomers was 0.42 ; [BVEEB + IBVE] $=0.1 \mathrm{~mol} \mathrm{1}^{-1}$; [Cat. $]=0.5 \mathrm{mmol} \mathrm{1}^{-1}$; time, $18 \mathrm{~h}$. 
Table IV. Synthesis of poly[(benzo-19-crown-6)-co-IBVE] by the copolymerization of 1,2-bis[2-(2-vinyloxyethoxy)ethoxy]benzene (BVEEB) and isobutyl vinyl ether (IBVE) with $\mathrm{BF}_{3} \cdot \mathrm{OEt}_{2}$ in $\mathrm{CH}_{2} \mathrm{Cl}_{2}$ at $0^{\circ} \mathrm{C}^{\mathrm{a}}$

\begin{tabular}{|c|c|c|c|c|c|}
\hline $\begin{array}{l}\text { Mole fraction } \\
\text { of BVEEB } \\
\text { in monomers }\end{array}$ & $\begin{array}{c}{[\mathrm{BVEB}+\mathrm{IBVE}]} \\
\mathrm{mol} \mathrm{l}^{-1}\end{array}$ & $\frac{\text { Time }}{\mathrm{h}}$ & $\begin{array}{c}\text { Yield } \\
\%\end{array}$ & $\begin{array}{l}\text { Mole fraction } \\
\text { of BVEEB units } \\
\text { in copolymer }\end{array}$ & $\begin{array}{l}\bar{M}_{n}^{\mathrm{c}} \\
\times 10^{-3}\end{array}$ \\
\hline 0.25 & 0.40 & 24 & 32 & 0.25 & 6.8 \\
\hline 0.42 & 0.40 & 18 & 40 & 0.50 & 6.3 \\
\hline 0.70 & 0.25 & 12 & 55 & 0.75 & 10.8 \\
\hline
\end{tabular}

a [Cat. $]=0.5 \mathrm{mmol} \mathrm{1}^{-1}$.

b Determined by ${ }^{1} \mathrm{H}$ NMR spectra.

c Determined by GPC (polystyrene standard).

Table V. Extraction of alkali-metal picrates by poly $\left[(\text { benzo-19-crown-6) })_{x}-c o-\mathrm{IBVE}_{y}\right] \mathrm{s}^{\mathrm{a}}$

\begin{tabular}{cccccc}
\hline $\begin{array}{c}\text { Molar ratio }(x / y) \text { of } \\
\text { benzo-19-crown-6 } \\
\text { and IBVE units } \\
\text { in polymer }\end{array}$ & \multicolumn{4}{c}{ Extraction yield $(\%)$ of the picrate } \\
\cline { 2 - 6 } & $\mathrm{Li}^{+}$ & $\mathrm{Na}^{+}$ & $\mathrm{K}^{+}$ & $\mathrm{Rb}^{+}$ & $\mathrm{Cs}^{+}$ \\
\hline $1.0 / 0$ & 8.4 & 36.3 & 81.6 & 91.2 & 82.5 \\
$0.75 / 0.25$ & 1.0 & 42.5 & 72.7 & 73.5 & 82.0 \\
$0.50 / 0.50$ & 4.6 & 34.0 & 71.0 & 68.0 & 84.0 \\
$0.25 / 0.75$ & 2.5 & 21.5 & 68.5 & 71.2 & 71.5
\end{tabular}

a [Picric acid], $7 \times 10^{-5} \mathrm{~mol}^{-1}$; [crown ether units in polymer], $3.5 \times 10^{-3} \mathrm{~mol}^{-1}$; [alkali-metal hydroxide], $0.1 \mathrm{~mol} \mathrm{1}^{-1}$

(BVEEB) with IBVE was similar to that for the BVEB-IBVE system, except that the former system was slower in the rate of polymerization than the latter one. The copolymerization parameters for BVEEB $\left(\mathrm{M}_{1}\right)$ and IBVE $\left(\mathrm{M}_{2}\right)$ were $r_{1}=1.23$ and $r_{2}=0.92$ whose values were very close to those for the BVEB-IBVE system. Figure 2 shows the ${ }^{1} \mathrm{H}$ and the ${ }^{13} \mathrm{C}$ NMR spectra of the copolymer with the mole fraction of BVEEB of 0.5. Because the characteristic absorption due to the vinyloxy protons (6.3-6.6 ppm) and carbons (86.7 and 151.6 ppm) disappeared in the ${ }^{1} \mathrm{H}$ and ${ }^{13} \mathrm{C}$ NMR spectra, the extent of cyclization in the BVEEB units was $100 \%$ and the cyclic constitutional units in the copolymer was benzo-19-crown-6.

The cation-binding property of the copolymers with crown ether units was estimated by

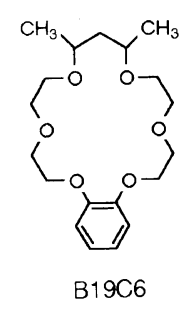

the one-plate extraction experiment using lithium, sodium, potassium, rubidium, and cesium picrates. Table IV lists four samples with the [BVEEB]/[IBVE] ratios of $1.0 / 0$, $0.75 / 0.25,0.5 / 0.5$, and $0.25 / 0.75$ used for the estimation of binding-property. Table $\mathrm{V}$ lists the extraction results of alkali-metal picrates by the polymers with benzo-19-crown-6 units. In the previous paper, we reported the cation-binding property of benzo-19-crown-6 (B19C6) which corresponds to the cyclic repeating units in the polymers. B19C6 showed the selectivity of $\mathrm{K}^{+}>\mathrm{Na}^{+}>\mathrm{Rb}^{+}>\mathrm{Cs}^{+} \gg$ $\mathrm{Li}^{+}$, which means that the diameter of the crown cavity agreed with that of $\mathrm{K}^{+} .5$ On the other hand, each of the polymers showed the similar cation-binding property, $\mathrm{K}^{+}, \mathrm{Rb}^{+}$, and $\mathrm{Cs}^{+} \gg \mathrm{Li}^{+}$and $\mathrm{Na}^{+}$, regardless of the composition of the copolymers. This cationbinding property of the copolymers can be explained, as well as that of the homopolymer of BVEEB, namely poly(benzo-19-crown-6), by cooperative coordination effects, where two neighboring crown ethers combine with a single 
$\mathrm{Rb}^{+}$and $\mathrm{Cs}^{+}$. However, there is a little difference among the extraction yields for ions of $\mathrm{K}^{+}, \mathrm{Rb}^{+}$, and $\mathrm{Cs}^{+}: \mathrm{Rb}^{+}>\mathrm{K}^{+}$and $\mathrm{Cs}^{+}$for the homopolymer, poly(benzo-19-crown-6), $\mathrm{Cs}^{+}>\mathrm{K}^{+}$and $\mathrm{Rb}^{+}$for the copolymers of the $0.75 / 0.25$ and the $0.5 / 0.5$ ratio, and $\mathrm{K}^{+} \approx$ $\mathrm{Rb}^{+} \approx \mathrm{Cs}^{+}$for that of the $0.25 / 0.75$ ratio. These results indicate that a difference of distance between two neighboring crown ethers and/or an introduction of oxygens for IBVE units slightly affects on the selectivity of the copolymers with the different molar contents of crown ether units.

\section{CONCLUSION}

Cationic cyclopolymerization of $\alpha, \omega$-divinylethers is a facile method for producing polymers with various types of crown ether units. Copolymerization of $\alpha, \omega$-divinylethers and vinyl ether with conventional cationic initiators proceeds without crosslinking reaction to give copolymers with various mole fractions of crown ether units. The high cyclization tendency of $\alpha, \omega$-divinylether in homo- and copolymerization is produced by the intramolecular solvation of the uncyclized growing-carbocation originating from $\alpha, \omega$ divinylether.

The copolymers consisting of BVEEB and IBVE units, namely, poly[(benzo-19-crown-6)-
co-IBVE]s, exhibit the high cation-binding property for $\mathrm{Rb}^{+}$and $\mathrm{Cs}^{+}$as well as for $\mathrm{K}^{+}$, regardless of the mole fraction of crown ether units. The crown units in the copolymer formed a 2:1 complex with $\mathrm{Rb}^{+}$or $\mathrm{Cs}^{+}$whose properties were very similar to these in poly(benzo-19-crown-6).

Acknowledgments. This investigation was supported by a Grant-in-Aid for Scientific Research (No. 03555193) from the Ministry of Education, Science, and Culture of Japan.

\section{REFERENCES AND NOTES}

1. G. B. Butler and Q. S. Lien, Cyclopolymerization and Polymer with Chain Ring Structure, ACS Symp. Ser., 195, 145 (1982).

2. L. J. Mathias and J. B. Canterberry, Cyclopolymerization and Polymer with Chain Ring Structure, ACS Symp. Ser., 195, 139 (1982).

3. K. Yokota, M. Matsumura, K. Yamaguchi and Y. Takada, Makromol. Chem., Rapid Commun., 4, 721 (1983).

4. T. Kakuchi, O. Haba and K. Yokota, Makromol. Chem., 192, 1601 (1991) and references cited therein.

5. T. Kakuchi, O. Haba and K. Yokota, Macromolecules., 25, 4854 (1992).

6. R. Rodenhouse, V. Percec and A. E. Fering, J. Polym. Sci., C, Polym. Lett., 28, 345 (1990).

7. T. Kakuchi, K. Aoki and K. Yokota, Polym. Prepr., Jpn., 39, 229 (1990).

8. G. B. Butler, J. Macromol. Sci., Chem., A5, 219 (1971). 